\title{
SUBJETIVIDADE E TRABALHO NA SOCIEDADE CONTEMPORÂNEA
}

\author{
SUBJECTIVITY AND WORK IN THE CONTEMPORANEOUS SOCIETY
}

Marcia Cavalcanti Raposo Lopes ${ }^{1}$

Resumo Este trabalho busca problematizar a relação sujeito-trabalho na sociedade contemporânea. De início, analisa as configurações dessa relação na história do ocidente, em especial a partir do final do século XVII. Num segundo momento, discute as especificidades dos novos processos de trabalho que vêm se consolidando em quase todo o planeta. A partir desse exame, constrói-se uma análise sobre as diferentes implicações sociopolíticas e subjetivas desta nova realidade da organização produtiva capitalista. Palavras-chave processo de trabalho; subjetividade contemporânea; acumulação flexível.
Abstract his article seeks to problematize the subjectwork relationship in the contemporaneous society. Firstly, it analyzes the configuration of this relationship in Western history, particularly as of the late 17th century. Secondly, it discusses the specificities of the new work processes that have been consolidating themselves nearly world-wide. Based on this examination, an analysis is built on the different sociopolitical and subjective implications this new reality in the capitalistic productive organization.

Keywords work process; contemporaneous subjectivity; flexible accumulation. 


\section{Introdução}

Num mundo marcado pela instantaneidade, pela avalanche contínua de informações e pela crescente exposição a diferentes ideias e valores, a construção de referências coletivas e a sensação de pertencimento a um grupo são processos problemáticos para os sujeitos contemporâneos. Imersos num universo onde os valores mercantis e o individualismo aparecem como articuladores nucleares das práticas sociais, os sujeitos têm as relações interpessoais marcadas pela competitividade, insegurança e busca de privacidade, tornando-se, cada vez mais, pontos perdidos e isolados em meio à multidão.

Eminentemente amalgamado à construção subjetiva em nossa cultura, o mundo do trabalho aparece como um ponto de referência fundamental para os processos de subjetivação contemporâneos. As complexas relações que se forjam no encontro (ou não-encontro) do sujeito com a atividade laboral compõem um eixo importante da dinâmica das sociedades capitalistas, constituindo-se, atualmente, em ponto central para o movimento de reestruturação produtiva.

Neste sentido, tenta-se neste texto apresentar algumas das discussões que vêm sendo travadas sobre o tema, considerando a reorganização dos espaços de trabalho, a produção de um novo trabalhador e a manutenção da ordem social vigente.

Vale ressaltar, desde já, que consideramos o mundo do trabalho, hoje, bastante heterogêneo ${ }^{2}$ e que muitas são as possibilidades de inserção dos sujeitos neste espaço. Entretanto, nossa discussão aponta para um estilo de ser trabalhador propalado como modelo de sucesso a ser buscado.

\section{Uma história sobre diferentes configurações do encontro sujeito-trabalho}

Recuando na história até a Grécia Antiga, vê-se facilmente como a relação sujeito-trabalho era marcada por variáveis bastante diferentes das que hoje definem este binômio, especialmente no mundo ocidental.

Como nos mostra Vernant (1989), a concepção de trabalho tal como o entendemos atualmente era inexistente e os contornos subjetivos se davam a partir de outros pontos referenciais que tinham na vida política seu ponto central.

O grego nem mesmo tem um termo que corresponda à palavra 'trabalho'. O vocábulo đovos aplica-se a todas as atividades que exigem esforço penoso e não somente às tarefas produtivas com valores socialmente úteis. 
(...) para que as várias atividades laboriosas se integrem umas com as outras e componham uma função psicológica unificada, é preciso que o homem, sob as formas particulares de cada tarefa, possa perceber sua própria atividade como trabalho em geral, o que só é possível no contexto de uma economia plenamente comercial, onde todas as formas de trabalho procurem igualmente criar produtos tendo em vista o mercado (Vernant, 1989, p. 35-36).

Além disso, de um modo geral, o homem não tinha, naquela época, o sentimento de transformar a natureza, mas, antes, de se adequar a ela e, igualmente, não tinha o sentimento de criar com seu esforço um valor social para sua tarefa ou seu ofício, qualquer que ele fosse.

A constituição subjetiva não tomará o trabalho como um de seus eixos centrais, os laços sociais são estabelecidos desvinculados do ofício,

no único plano em que os cidadãos podem amar-se reciprocamente porque nele todos se comportam de maneira idêntica e não se sentem diferentes uns dos outros: o das atividades não profissionais, não especializadas, que compõem a vida política e religiosa da cidade (Vernant, 1989, p. 37).

Recuando na história por um tempo bem menor - até mais ou menos o século XVIII -, é possível ver se desenhar, no ocidente, o entrelaçamento dos fios que teceram a estreita ligação entre trabalho e subjetividade tal como se dá hoje e que, atualmente, nos parece quase inerente à natureza humana.

Percebe-se, no final do século XVIII, na Europa ocidental, um reordenamento dos processos sociais que ao mesmo tempo viabilizam e são viabilizados por um novo padrão de racionalidade, uma nova sociabilidade e, é claro, um novo sujeito.

A atividade laborativa vai tornar-se, então, como veremos, uma categoria central para pensar a vida social e, consequentemente, o ser humano. Contorno obrigatório de quase toda atividade que traz reconhecimento aos sujeitos, o trabalho, tal como o entendemos hoje, constituir-se-á em ponto fundamental da ontologia humana até os tempos atuais.

Em sua fase pioneira, ainda marcada pelo legado técnico e cultural dos artesãos, a nova ordem social que se fundamentava no trabalho fabril enfrentou enormes resistências por parte do conjunto dos trabalhadores - nova categoria que se forjava no seu interior e essencial ao seu funcionamento.

Eles (...) resistiam às mudanças em suas práticas culturais e valores, em seu modo tradicional de vida e no modo artesanal de trabalhar. A moral do industrialismo era um golpe no espontaneísmo da cultura popular, sendo uma de suas 
expressões a rotina semanal pontuada de festas, feiras e enterros que comprometiam a regularidade do trabalho fabril (Colbari, 2001, p. 115).

Era necessária a interiorização de uma 'ética' do novo trabalho - de um conjunto de variáveis que os trabalhadores deviam estar dispostos a exercer, tais como o cumprimento voluntário dos horários, regulamentos e ordens específicas, o cuidado com ferramentas, atenção e precisão no trabalho executado etc.

Esta interiorização é necessária para a consolidação da Revolução Industrial que, além de significar a vitória do sistema fabril sobre formas anteriores de organização da produção, vai produzir uma nova moral e uma nova concepção de mundo ancorada na substituição das antigas e ineficazes formas coercitivas de controle dos trabalhadores, muito mais baseadas em punições, por formas disciplinares mais sutis e eficientes ${ }^{3}$. Uma constituição singular do binômio trabalho-subjetividade começa a se materializar aí, promovendo o nascimento do 'trabalhador moderno'.

A gradativa materialização das sociedades ocidentais modernas testemunha, assim, o entroncamento da formação subjetiva com as atividades profissionais, que dá ao trabalho um lugar central na conformação sociossubjetiva moderna. Inclui-se na categoria trabalho, aqui, não apenas o exercício de uma determinada profissão, mas também os modos de trabalhar, as formas de conquista de um espaço no mercado de trabalho e, até mesmo, os contextos que definem a exclusão do trabalho.

O trabalho vai tornar-se, paulatinamente, a forma por excelência de relação e ação do sujeito sobre o mundo. Assim, a dimensão ontológica da automediação do trabalho converte-se, como observa Ramos (2004), no ponto de partida para a produção de cultura pelos grupos sociais, entendendo esta como "processo de produção de símbolos, de representações, de significados e, ao mesmo tempo, prática constituinte e constituída do/pelo tecido social" (Ramos, 2004, p. 45).

O contexto econômico europeu do final do século XIX e início do XX foi marcado por uma crise à qual se segue uma nova onda de transformações e a emergência de um novo paradigma tecnológico - inovações importantes na base técnica do processo produtivo - e de um novo padrão de desenvolvimento.

Este momento, identificado como Segunda Revolução Industrial, assiste à invenção da administração científica do trabalho, que vem responder às dificuldades ainda existentes, naquela época, no que tange a normalizar as relações de trabalho (alto índice de rotatividade e absenteísmo da mão-de-obra, contestação coletiva da disciplina etc.). 
Tem início a era do taylorismo e do fordismo, que inovou as formas de organização do trabalho e o sistema de autoridade fabril, ambos orientados para a criação de um novo tipo de trabalhador, mais produtivo e mais disciplinado. (...) Com a chamada organização científica do trabalho, o processo de produção foi dissociado das qualificações dos trabalhadores; a concepção (a dimensão inteligente, criativa) foi separada da execução do ato do trabalho; a gerência assumiu o monopólio do conhecimento (Colbari, 2001, p. 116-117, grifos nossos).

Já no século $\mathrm{XX}$, este trabalho absolutamente simplificado, realizado sob tempos e movimentos minuciosamente programados e cronometrados, além de garantir uma elevada produtividade, promoveu a desqualificação das atividades laborais e 'elevou' o trabalhador à condição de consumidor fatores fundamentais para sobrepujar a crise econômica da época e realimentar o capitalismo ocidental, alavancando o crescimento e a difusão do que se chamou 'Estado do Bem-Estar Social'.

Como nos mostra Colbari (2001):

(...) os efeitos do fordismo transbordaram os limites da fábrica e invadiram outras esferas da sociedade, alicerçando um tipo de engenharia social e política, um pacto de compromisso sustentado por salários mais elevados e um conjunto de mecanismos de proteção social, patrocinados pelo Estado [o que consubstancia o 'Estado do Bem-Estar Social'], que compensava os efeitos negativos gerados na esfera do mercado (Colbari, 2001, p. 119).

As novas ferramentas gerenciais, como se vê, não têm efeitos apenas no âmbito dos processos de trabalho, elas são produto/produtoras de um novo desenho político-social e consequentemente também de uma reorganização subjetiva onde as noções de identidade e trabalho ficam ainda mais coladas e se tornam mais solidamente estruturadas.

Assim, a consolidação do fordismo no pós-guerra e o fortalecimento do Estado do Bem-Estar Social no chamado primeiro mundo forjam a sociedade da produção em massa, rígida, vagarosa - se comparada aos tempos atuais - e, em alguma medida, protetora, com um desenho absolutamente nítido de seus contornos e de seus sujeitos.

Todo este processo instaurado, a princípio no oeste da Europa e nos EUA, tem evidentemente repercussões nos países periféricos do ocidente. No Brasil, o princípio da industrialização nacional, no final do século XIX e início do XX, vai impulsionar igualmente um projeto sutil de 'disciplinarização' das classes populares.

Como nos mostra Rago (1997): 
Percebidos como selvagens, ignorantes, incivilizados, rudes, feios e grevistas, sobre os trabalhadores urbanos que compõem a classe operária em formação nos inícios da industrialização no Brasil constitui-se paulatinamente uma vasta empresa de moralização. Seu eixo principal: a formação de uma nova figura do trabalhador, dócil, submisso, mas economicamente produtivo; a imposição de uma identidade social ao proletariado emergente, se assim já podemos chamá-lo (Rago, 1997, p. 12).

Os anos 70, entretanto, testemunham o início do abalroamento dos pilares de sustentação deste sistema. Desde então, o mundo ocidental vem assistindo a uma grande reconfiguração de suas práticas sociossubjetivas, que atinge quase todo o planeta num movimento chamado de 'globalização'. Todo este processo não acontece sem profundas mudanças no 'mundo do trabalho'. Mudanças que se caracterizam por uma ação recíproca sobre este curso de reconfiguração sociopolítica, constituindo-se não só num importante ponto de impulsão, mas também num de seus principais efeitos.

A profunda recessão de 1973 põe em movimento um conjunto de processos que vão gradativamente redesenhar o campo da produção.

(...) as décadas de 70 e $80^{4}$ foram um conturbado período de reestruturação econômica e de reajustamento social e político. No espaço social criado por todas estas incertezas, uma série de novas experiências pode representar os primeiros ímpetos da passagem para um regime de acumulação inteiramente novo, associado com um sistema de regulamentação social bem distinta (Harvey, 2001, p. 140).

Desenvolve-se, então, o que hoje se designa por acumulação flexível.

Apoiado na flexibilidade dos processos de trabalho, dos mercados de trabalho, dos produtos e padrões de consumo, impulsionado pelas novas tecnologias da informação, o regime de acumulação flexível vem justamente corroer a enorme rigidez dos processos fordistas, reestruturando o sistema produtivo e promovendo efeitos significativos na conformação subjetiva contemporânea.

Esta reestruturação produtiva, que marca o início da década de 1970, vem incorporando um novo padrão tecnológico e organizacional que tem por objetivo suplantar a crise gerada nesses anos com sistemas de trabalho mais eficientes e com maior produtividade.

Em relação ao mercado de trabalho, pode-se apontar, conforme as análises atuais, duas tendências contraditórias: uma vertente releva a precariedade e a desproteção que marca o sistema de trabalho contemporâneo; a outra indica a valorização do trabalho qualificado e o resgate do saber do trabalhador. Além disso, uma acirrada competição pelos postos de trabalho, 
cada vez mais difíceis, produz um individualismo crescente onde o poder coletivo dos trabalhadores se vê progressivamente mais abalado.

Novas teias se produzem neste campo que define o binômio subjetividade-trabalho. A realidade do sistema produtivo, que começa a ganhar forma, combina velhos mecanismos de controle e vigilância, como remuneração e promoções, com o investimento na motivação, na participação e no envolvimento do trabalhador com seu trabalho. "Os mecanismos de controle sobre o trabalho, internalizados pelo trabalhador, devem potencializar o envolvimento, a cooperação e a responsabilidade" (Colbari, 2001, p. 122), produzindo, em consequência, um 'sujeito trabalhador'5 diferenciado, ao mesmo tempo que uma nova estrutura sociopolítica.

Assim como no processo de disciplinarização, toda essa nova reorganização socioprodutiva e subjetiva, que já é bastante visível no primeiro mundo, também chegará ao Brasil com um pequeno atraso. Neste sentido, vale ressaltar que esta tendência, embora já seja perceptível em alguns processos produtivos em nosso país, não pode ser ainda considerada como padrão, indicando apenas um movimento de transformação.

\section{Novos processos de trabalho e subjetividade}

A reorganização produtiva que marca a contemporaneidade, como foi apontado, é, na verdade, apenas, uma das pontas de uma grande transformação por que vem passando quase todo o planeta, capitaneada pelo mundo ocidental. Evidentemente, ela envolve uma nova relação sujeito-trabalho-mundo, que compete com as antigas estruturas sociossubjetivas 6 do capitalismo.

Em um mundo produtivo cada vez mais fluido, onde a matéria física, pelo menos das empresas de ponta, é leve e de vida reconhecidamente curta, onde não só as máquinas, mas também os produtos do trabalho são continuamente cambiados, onde a tecnologia assume cada vez mais a parte mecânica da produção e substitui um quantitativo grande de mão-de-obra, ao sujeito-trabalhador caberá um novo espaço, extremamente disputado e competitivo, com novas regulações, com novas exigências e requisitos, impelindo os sujeitos à construção de novos padrões, valores e relações no trabalho, e também fora dele.

Entre as principais características desta nova realidade, pode-se citar: a redução estrutural dos postos de trabalho e a precarização dos vínculos trabalhistas; a maior competitividade do mercado e a exigência contínua de individualização e inovação da produção; a flexibilização da organização do trabalho; a dinamização das tarefas e atividades e a consequente necessidade de maior qualificação e polivalência dos trabalhadores. Todos estes 
fatores, junto a uma nova postura do Estado, terão efeitos decisivos na vida do trabalhador.

A expansão da insegurança do trabalho é evidente e se dá "tanto no nível do mercado de trabalho quanto no emprego, na renda, na contratação e na representação do trabalho" (Fonseca, 2002, p. 19).

Assim, se as relações de trabalho características do taylorismo-fordismo, que se pautaram por uma certa padronização e normalização dos sujeitos, por trabalhos mecânicos e 'rotinizados', produziam determinada sociedade capitalista que tecia relações de solidariedade, envolvendo não só o conjunto dos trabalhadores entre si, mas também trabalhadores e Estado, que, em alguns momentos, sob a pressão dos trabalhadores, podia proteger os sujeitos das agruras impostas pelo capital, as novas estruturas produtivas individualizam cada vez mais o trabalho e sua regulação, dispondo única e exclusivamente sobre os ombros de cada trabalhador a responsabilidade de sua inserção social.

Ramos (2001) observa argutamente:

O aumento da flexibilidade das relações sociais de produção interna e externa às organizações produtivas é responsável por desatar [os] laços de solidariedade e de seguridade. A flexibilidade interna, funcional à automação da produção, baseiase na polivalência, no diferencial de responsabilidade, carreiras e salários de uma mesma categoria, bem como no uso, por parte dos empregadores, de estratégias também diferenciadas de cooptação e estímulo à participação dos trabalhadores na produção. A flexibilidade externa, voltada a facilitar os ajustes da oferta da força de trabalho periférica, permite a desregulamentação das relações trabalhistas, que pode vir acompanhada de uma precarização baseada nos contratos temporários, de tempo parcial e na subcontratação. A conjugação desses tipos de flexibilidade fomenta a individualização do trabalho não só em termos técnicos, mas também em termos sociais, na medida em que coloca o conjunto de trabalhadores em situação de vulnerabilidade e de insegurança quanto à conquista e à manutenção do emprego (Ramos, 2001, p. 173-174).

Toda esta nova situação, construída como uma 'evolução natural' do modelo produtivo, é um espaço fértil na constituição do 'trabalhador competente', versátil, que deve vivenciar a flexibilidade e a insegurança das condições de trabalho como um desafio inevitável na sua vida profissional.

A noção de competência não só se torna categoria ordenadora das relações sociais de trabalho, no interior das empresas, como também passa a cumprir o papel de ordenadora das relações sociais de trabalho externamente às organizações produtivas - no sentido de gerir as condutas e reconfigurar os valores ético-políticos dos trabalhadores no contínuo processo de conformação à instabilidade social - e ganha, assim, uma importância 
fundamental na formação dos sujeitos do século XXI e, é claro, no conjunto da vida social.

A regularidade de uma carreira em uma empresa, a disciplina dos horários, a especialização em uma atividade determinada, a vida regrada e o adiamento das satisfações em prol da segurança garantida no futuro vão deixando de ser pontos cruciais da profissionalidade, cedendo espaço para uma nova lógica fundada numa 'ética' do trabalho diferenciada, autocentrada e competitiva.

Neste ponto, vale lembrar que nas entrelinhas de toda esta discussão, construída a partir de um olhar panorâmico, existe o cotidiano de trabalho de diferentes trabalhadores de 'carne e osso', com diferentes funções e valores e diferentes formas de gerir esse cotidiano, que se veem consideravelmente ampliadas - para o bem ou para o mal - com o gradativo declínio do fordismo.

\section{A gestão por competência e a formação do novo sujeito-trabalhador}

Esta nova organização do trabalho que vem se consolidando em todo o planeta configura um mundo produtivo com características tendenciais importantes que redesenham as relações sujeito-trabalho: a reestruturação das ocupações; a multifuncionalidade e polivalência dos trabalhadores; e a valorização dos saberes não ligados ao trabalho prescrito ou ao conhecimento formalizado. Assim, uma nova codificação da atividade laboral tende a exigir um trabalhador diferenciado, que não mais se encaixa no perfil do 'operário especializado' que se limita a conhecer e repetir os procedimentos restritos e rotineiros de um determinado posto de trabalho. A lógica que demarcava os espaços do sujeito no sistema fordista, mesmo que persistente, tende gradativamente a desvanecer como modo central, favorecendo uma nova configuração do trabalhador ideal.

Toda essa reorganização do processo produtivo traz para o centro da discussão sobre a produtividade e adequação dos recursos humanos o conceito de competência, colocando em um novo formato as expectativas quanto ao trabalhador, moldando um novo enquadramento sujeito-atividade, onde a 'velha' noção de qualificação já não responde mais às necessidades.

A esse respeito, Ramos (2001) observa:

Com o advento das novas tecnologias e sistemas de organização do trabalho - processo chamado genericamente de reestruturação produtiva - (...) a qualificação [do trabalhador] entrou numa fase em que, sob alguns aspectos, é tomada como pressuposto da eficiência produtiva; por outros, ela tende a ser abandonada como conceito organizador das relações de trabalho e de 
formação dando lugar à noção de competência. Alguns aspectos passam a ser valorizados em nome da eficiência produtiva: os conteúdos reais do trabalho, principalmente aqueles que transcendem ao prescrito e às qualidades dos indivíduos expressas pelo conjunto de saberes e de saber-fazer realmente colocado em prática, incluindo para além das aquisições de formação, seus atributos pessoais, as potencialidades, os desejos, os valores (Ramos, 2001, p. 53, grifos nossos).

Na realidade, seguindo as análises de Ramos (2001), percebe-se claramente como a competência torna-se categoria ordenadora das relações sociais de trabalho, tanto interna como externamente às organizações produtivas.

A incorporação do trabalho pelas máquinas e a interatividade que se estabelece entre produtor e consumidor, visando à qualificação e à individualização dos produtos, reposicionam a atividade humana, que deixa de ser mecânica e previsível e passa a exigir não só criatividade, mas também a capacidade de enfrentar os acontecimentos imprevistos, os eventos7. A competência profissional deixa de ter, como referência fundamental, predefinições de tarefas a serem efetuadas nos postos de trabalho. Ela se refere essencialmente ao indivíduo e à sua possibilidade de análise e ação frente aos eventos.

O uso do termo competência vem expressar as mudanças na gestão da produção e está associado a atributos que são adequados àquelas como autonomia, iniciativa e responsabilidade e ao questionamento da qualificação profissional formal. Esse termo (no singular) abarca um conjunto de competências (no plural) particulares que se referem às modificações específicas que se processam nas atividades profissionais e que se apresentam como propriedades instáveis dentro e fora do exercício do trabalho, implicando uma permanente avaliação do trabalhador, não só da sua capacidade técnica, mas também do desenvolvimento de características pessoais que permitam sua adequação ao 'posto de trabalho'.

Nesse contexto, a classificação e a progressão do indivíduo no trabalho fica desligada de uma classificação por qualificação formal, e a categorização dos empregos passa a ocorrer muito mais em função de arranjos particulares.

Em conformidade com a discussão de vários autores, Ramos (2001) aponta como a noção de competência entendida como um conjunto de propriedades instáveis que devem ser submetidas à prova acaba por opor-se à qualificação avaliada socialmente pelo título adquirido para sempre e à própria ideia de profissão. Ressalte-se, aqui, que as competências podem ser adquiridas em experiências diferentes da educação formal, sendo tratadas como características do indivíduo e não remetidas a uma categoria forma- 
lizada. A noção de competência, assim, não justificaria a reivindicação de quaisquer direitos coletivos.

Neste sentido, escreve Ramos (2001):

A competência passa a estar no princípio da organização do trabalho, no lugar da qualificação/profissão. Enquanto o domínio de uma profissão, uma vez adquirido, não pode ser questionado (no máximo, pode ser desenvolvido), as competências são apresentadas como propriedades instáveis dentro e fora do exercício de trabalho. Significa dizer que uma gestão fundada na competência encerra a ideia de que um assalariado deve se submeter a uma validação permanente, dando constantemente provas de sua adequação ao posto, de seu direito a uma promoção ou a uma mobilidade promocional (Ramos, 2001, p. 194).

Como se vê, a noção de competência é uma categoria eminentemente individual e acaba por embasar procedimentos que particularizam cada trabalhador, justificando seu sucesso ou fracasso em função de suas próprias capacidades, exigindo dele um envolvimento e um movimento de 'evolução' contínuo em relação a suas tarefas. Além disso, faz prevalecer o princípio de pertencimento do trabalhador à empresa, muito mais do que seu pertencimento a uma sociedade, a uma classe ou a uma categoria de trabalhadores.

Vale observar, seguindo Zarifian (2001), que em termos objetivos a gestão por competência se organiza em torno de quatro eixos fundamentais: gestão individualizada dos trabalhadores; desenvolvimento das competências individuais; reconhecimento das competências adquiridas pelo trabalhador, independentemente da forma como as tenha adquirido; e remuneração em função destas competências. E estes eixos implicam alguns procedimentos - como analisar, identificar, repertoriar permanentemente as competências requeridas pelos empregos e as adquiridas pelos trabalhadores; desenvolver instrumentos de gestão previsional das competências e desenvolver dispositivos de aquisição de competências - que, indubitavelmente, vão exigir que estas se tornem visíveis e passíveis de avaliação. Esta avaliação, entretanto, envolve um processo complexo e de difícil dimensionamento, já que precisa dar conta não só do contexto onde se exercem as competências, mas também do intricado movimento dialético de construção e uso de seus diferentes ingredientes.

Sobre o tema, deve-se destacar o trabalho de Schwartz (1998), que discute seis diferentes ingredientes da competência, 8 que têm uma relação dialética entre si e impedem a construção de um dispositivo único para sua avaliação e classificação. Além disso, Schwartz aponta a dependência efetiva existente entre o desenvolvimento das competências e o contexto em que os trabalhadores estão inseridos, o que impossibilitaria uma ótica plenamente objetiva no processo de avaliação. 
Retomando nossas análises, a despeito das contribuições anteriores que sofisticaram um trabalho concreto de avaliação, é possível afirmar que a noção de competência se coloca como categoria de representação

(...) que permite estabelecer uma adequação entre a análise do trabalho, suas modalidades de organização e as capacidades individuais dos trabalhadores. Permite, também, adaptar os requisitos dos empregos às exigências novas em termos de profissionalização, sempre com vistas à adaptabilidade do trabalhador, seja internamente à organização ou quando desligado de um emprego formal (Ramos, 2001, p. 198).

A primazia do desempenho individual parece acobertar as contradições inerentes ao sistema capitalista, dando uma certa legitimidade às diferenças sociais e destinando a cada um a responsabilidade pela sua situação.

Além disso, a 'personalidade' do trabalhador e sua atitude no trabalho acabam sendo parâmetros determinantes para sua contratação e permanência no emprego. Exige-se continuamente o comprometimento efetivo do sujeito com sua atividade, convocando-se irremediavelmente a subjetividade para o centro dos processos de trabalho. É a potência transformadora e criadora dos sujeitos que é requisitada como ponto chave nos processos produtivos que se tornam, portanto, bem mais dependentes da sensibilidade humana.

Surge neste processo um novo modelo de trabalhador, não mais um executor disciplinado de funções predefinidas, mas "um ser que une a ação e o pensar em nome de 'saber ser responsável'" (Rosa, 1998, p. 136); constrói-se a expectativa de um trabalhador autônomo, comprometido com o que faz, capaz de reinventar continuamente o seu trabalho e se organizar frente aos acontecimentos inesperados.

Desta maneira, juntamente com os contornos sociais, a configuração do trabalho não só vem perdendo sua rigidez e tornando fluidas e individualizadas as amarras que conformam o trabalhador contemporâneo, mas também vem se oferecendo de forma diferenciada como espaço importante de investimento subjetivo, esfera de possibilidade dos processos de subjetivação.

Neste sentido, como analisa Fonseca (2002), é importante nos perguntarmos:

(...) estamos assistindo a um movimento - entre tantos do cotidiano - de desterritorialização dos 'eus', que poderiam ser entendidos como potencializadores da reinvenção da existência, ou (...) as experiências de desestabilização e estranhamento impostas aos sujeitos do trabalho além de provocarem o mal-estar inevitável (mas dotado, teoricamente, de potencial de superação e absorção), 
constituem-se em experiências traumáticas invertidas em sua potencialidade criadora, desejante, produtora (Fonseca, 2002, p. 23).

Coloca-se, então, a questão: este novo paradigma de organização da produção, que se contrapõe ao sistema de produção em massa, pode ser visto como propiciador do enriquecimento da atividade laboral, produtor de um trabalhador completo e precursor do fim da divisão do trabalho e da possibilidade de reunião do binômio produção-desejo? Ou envolveria uma lógica de adequação das relações sociais de trabalho ao contexto de crise da acumulação capitalista, "concretamente expressa pelos altos índices de desemprego, pela fragilidade dos laços de identidade, pela retração dos direitos sociais e outros tantos fenômenos que convergem para o acirramento do individualismo" (Ramos, 2001, p. 198, grifos nossos) e a manutenção das injustiças sociais? Ou todos esses movimentos se fazem presentes?

\section{Problematizando as relações sujeito-trabalho}

Em um modelo de organização social no qual os espaços de troca são cada vez mais raros e circunscritos a objetivos determinados de produção, em uma sociedade cujos caminhos nos empurram cada vez mais para espaços privatizantes, individualizantes e onde os processos de identificação estão em erosão, a nova organização do trabalho - com funções e atividades não mais prescritas e parceladas, a consequente valorização das atitudes frente aos eventos inesperados e propostas de trabalho em equipe - vem se oferecer, em princípio, como um raro espaço coletivo, onde as pessoas se encontram, onde a subjetividade se vê continuamente solicitada a produzir e se produzir.

Este espaço é ainda mais reforçado pelo lugar estratégico e socialmente valorizado e pela função ontológica do trabalho nas sociedades ocidentais, que discutimos anteriormente. Como nos mostra Dejours (1992):

O trabalho é um dado fundamental da saúde. Não somente de maneira negativa (o trabalho como causa de doenças, de intoxicações, de acidentes, de desgaste etc.), mas também de forma positiva. O não trabalho também pode ser perigoso para a saúde, como se vê bem, atualmente, com toda a patologia do desemprego (Dejours, 1992, p. 102).

Mas como se constitui este espaço? Que contornos de vida e trabalho se forjam para o trabalhador a partir das novas condições e exigências das funções laborais? 
As discussões trazidas por Schwartz (2004) nos ajudam a complexificar estas indagações. Considerando a noção de gestão como o verdadeiro problema humano - já que ela sobrevém em todos os momentos onde é necessário dar conta de algo sem recorrer a procedimentos previamente fixados, onde há história e variabilidade, onde se supõe escolhas e hierarquização de valores em nome dos quais essas escolhas se fazem - e inserindo esta noção como ponto fundamental das análises sobre a questão do trabalho, ele defende o redimensionamento da problematização das relações sujeito-trabalho.

Como nos diz o autor, todo trabalho é uso de si, considerando, aqui, simultaneamente, uso de si por outros (o que vai das normas econômicoprodutivas às normas operacionais) e uso de si por si mesmo (que envolve os compromissos e valores do próprio sujeito). O que indica uma dramática sempre presente nas atividades industriosas que envolvem a gestão do uso de si.

Recoloca-se, aqui, a questão da densidade do espaço de trabalho, ${ }^{9}$ fundamental de ser entendida no que se refere ao envolvimento do trabalhador com sua própria atividade e os efeitos sofridos por ele quanto ao seu bemestar e à sua saúde. Torna-se indispensável considerar o debate de normas que está presente nas diferentes atividades de trabalho, ou seja, a tentativa de encontrar um equilíbrio entre normas de cada um, do coletivo, de uma organização e do universo político no qual se está inserido.

Ao analisar a nova organização da produção como propiciadora de uma margem maior de possibilidades nesta reinvenção contínua da díade sujeitotrabalho alargando o espaço de gestão do trabalhador em sua atividade, em princípio poderíamos ser levados a pensá-la como um contexto duplamente positivo: por um lado, com efeitos bastante interessantes para a construção subjetiva desses trabalhadores; por outro, favorecedora, em alguma medida, do movimento e da transformação das atividades e das relações no trabalho e, como extensão consequente, fora dele.

Assim, assumindo como parâmetro a noção de saúde proposta por Canguilhem (1990) e utilizada por Schwartz, o que implica colocar como referência fundamental da vitalidade dos sujeitos a capacidade de instaurar novas normas frente a situações adversas e considerando que a relação saúde-atividade laboral nunca pode ser pensada desvinculada da experiência dos trabalhadores e de suas possibilidades de ação e transformação de si e do meio de trabalho, em princípio o sistema produtivo emergente se insinuaria como um ponto de apoio importante na promoção de saúde dos sujeitos e de um movimento de reordenação da lógica sociopolítica contemporânea.

Entretanto, neste ponto faz-se necessário repensar os fios que entrelaçam esta díade com mais cuidado, no sentido de entender as possibili- 
dades de relação e conquista da saúde e do bem-estar dos sujeitos em seu trabalho, assim como sua possibilidade de transformação dos processos produtivos e sociais.

Não se pode, é claro, desconsiderar estas análises, que implicam uma problematização cuidadosa e particular das incontáveis relações construídas pelos trabalhadores em seus postos de trabalho. Entretanto, mesmo levando em conta sua extrema importância ao devolver aos trabalhadores o papel ativo no processo de acomodação do binômio sujeito-trabalho, retirando-lhes do lugar de vítimas indefesas de um sistema, parece-nos fundamental rediscutir alguns pontos que subjazem esta nova estrutura laboral que vem se consolidando no mundo.

Seguindo nossas análises sobre os liames contemporâneos que se produzem na interseção subjetividade-trabalho, faz-se necessário um exame crítico das relações que constroem grande parte das relações humanas e dos espaços grupais nas renovadas organizações produtivas.

Como nos mostra Sennett (1999), embora valorizando o trabalho em equipe e propiciando espaços de produção grupais, a nova organização do trabalho é atravessada por um conjunto de aspectos que, muitas vezes, não são discutidos e que têm efeitos decisivos nos contornos que o trabalho toma para os sujeitos: a falta de uma trajetória temporal característica de uma economia política continuamente replanejada, que despreza qualquer rotina e tem seus objetivos amarrados ao curto prazo; a competitividade - mesmo escamoteada - que se produz numa sociedade onde a única 'identidade' aceitável é a de vencedor; e as contradições - ainda que encobertas - das relações 'líder-liderados' (leia-se chefia-funcionários).

Cria-se, então, quase sempre, uma comunidade fictícia sem relações humanas constantes e objetivos duráveis, sem relações de confiança e com a presença de relações de poder dissimuladas sem que se efetive a figura de autoridade que lhe corresponde. 10

Com tudo isto, dificilmente seria possível um processo de 'cumplicidade' que envolva, através da vivência das diferenças e dos conflitos, a construção coletiva de referências e a produção de cultura, de conhecimento, de contornos subjetivos que escapem à lógica consumista das sociedades contemporâneas.

Na realidade, como vemos, o 'novo capitalismo' traz consigo algumas armadilhas. As novas relações que se constroem nos espaços de trabalho, embora pareçam favorecer os trabalhadores - e, por vezes, em certo sentido, efetivamente favorecem - quando olhadas mais detidamente se mostram nefastas, impondo novos controles e estruturando um sistema de poder de difícil leitura para os sujeitos.

Por um outro foco de análise, seguindo as discussões da psicodinâmica 
do trabalho de Dejours (1992; 1994; 1999), também é possível problematizar a mesma questão.

Como nos apontam Dejours, Abdoucheli e Jayet (1994), não é possível definir uma organização do trabalho que coloque os sujeitos ao abrigo do sofrimento. Contudo, é preciso considerar a bivalência deste sofrimento. Por vezes, observa-se que este último emerge quando as possibilidades de ajustamento do sujeito à organização do trabalho para colocá-la em concordância com seu desejo já foram esgotadas - neste caso, estamos falando do sofrimento patogênico. Por vezes, entretanto, o sofrimento propicia a criação pelos trabalhadores de procedimentos específicos que vão além da simples adaptação aos processos de trabalho - falamos, então, do sofrimento criativo.

Estes procedimentos resultam da mobilização de processos psíquicos pelos sujeitos, que podem estar ligados a uma forma específica de inteligência - a inteligência astuciosa - que tem raiz no corpo, na percepção e na intuição sensível e que, embora derive do sofrimento, propicia, como contrapartida de seu exercício, o prazer.

Para a ativação desta inteligência, no encontro do trabalhador com a situação de trabalho, entretanto, é necessário não só que o sujeito possa dar um sentido a sua tarefa, mas também que ela seja reconhecida e validada socialmente, sendo estas, portanto, condições fundamentais na construção de um espaço de trabalho prazeroso e profícuo.

Neste sentido, o fordismo - caracterizado por atividades absolutamente simplificadas, parceladas e desvalorizadas - só poderia ser tomado como extremamente nocivo para os trabalhadores. 11 Já a nova organização do trabalho - caracterizada pela flexibilidade e por oferecer maior 'liberdade' para os trabalhadores; pela valorização da criatividade e desenvolvimento dos sujeitos - pelo menos aparentemente resgataria a possibilidade de investimento subjetivo dos indivíduos, proporcionando espaço para o exercício da inteligência astuciosa.

Contudo, apesar de estimular a autonomia e a participação dos trabalhadores e de valorizar o trabalho em equipe, propiciando, em tese, a troca e o reconhecimento mútuo dos indivíduos, a organização flexível tem um cunho extremamente individualista, que estimula o isolamento e a competição entre os trabalhadores, nem sempre favorecendo o clima de confiança que permite o envolvimento efetivo dos sujeitos com seu trabalho, assim como com o processo de construção coletiva das tarefas e, portanto, de validação social da atuação dos membros da equipe.

Tomando ainda um outro prisma de análise, é preciso problematizar, neste ponto, a própria noção de autonomia que se coloca como ganho no sistema de produção emergente. Ao discutir justamente esta questão, Gorz (2003a) adverte que todo trabalho desenvolve-se em três dimensões - a or- 
ganização do processo de trabalho; a relação com o produto que o trabalho tem por fim realizar e os conteúdos do trabalho; e a natureza das atividades que ele requer e as faculdades humanas que ele demanda - e que não basta restituir-lhe autonomia em uma delas para que se torne, de fato, uma atividade autônoma. 12

Assim, diz Gorz, em relação à primeira dimensão:

O trabalho em grupos autônomos, cujos membros repartem entre si as tarefas, revezam-se, auto-organizam seus trabalhos, ocupam-se das máquinas e controlam eles mesmos a qualidade do produto, reduz fortemente o grau de heteronomia que caracterizava o trabalho parcelizado do taylorismo. Porém não suprime a heteronomia; ele simplesmente a desloca. A heteronomia, com efeito, caracteriza as atividades especializadas que os indivíduos cumprem como funções coordenadas do exterior, por uma organização, em vista de um fim preestabelecido (Gorz, 2003a, p. 83).

Evidentemente, a natureza das tarefas é predeterminada e os indivíduos funcionam como engrenagens de uma grande máquina.

Em relação à segunda dimensão, ainda se reportando às novas formas de produção, Gorz salienta:

A alienação do produto é, por certos aspectos, ainda mais completa que na fábrica taylorizada. Os profissionais especializados de cada grupo polivalente não têm mais aquela habilidade de produtor que, apesar de tudo, os operários especializados detêm: jamais intervêm no produto ou no semiproduto, isto é, no material; intervêm apenas nas máquinas que trabalham o material (Gorz, 2003a, p. 84).

Já considerando a terceira dimensão, Gorz argumenta:

O interesse e a variedade de um trabalho não bastam para transformá-lo em um trabalho humanamente satisfatório. Claro, um trabalho no qual invisto a mim mesmo sempre vale mais que uma tarefa repetitiva. Mas a questão fundamental é saber em que medida os conhecimentos e as faculdades que um trabalho mobiliza constituem uma cultura profissional e em que medida há unidade entre a cultura profissional e a cultura do cotidiano: entre o trabalho e a vida. Em que medida, em outros termos, o investimento no trabalho implica enriquecimento pessoal ou, ao contrário, desinvestimento em si mesmo? Ao fim da minha jornada, tornei-me humanamente mais rico ou mais pobre? (...) Trabalhar não é apenas produzir riquezas econômicas; sempre é, também, uma maneira de produzir a si mesmo. A questão que precisa ser formulada a propósito dos conteúdos do trabalho, portanto, deve ser também esta: estamos diante de homens, de mulheres, dos quais gostaríamos que a humanidade fosse feita? (Gorz, 2003a, p. 84-85). 
Em discussão sobre a banalização da injustiça social que caracterizaria a sociedade contemporânea, Dejours (1999) segue uma linha semelhante à linha de argumentação de Gorz, quando nos mostra como esta nova organização do trabalho referenda uma razão economicista inerente ao contexto mais amplo de injustiça e exclusão social em que ela se insere. Neste sentido, nos diz o autor:

A exclusão e a adversidade infligidas a outrem em nossas sociedades, sem mobilização política contra a injustiça, derivam de uma dissociação estabelecida entre adversidade e injustiça, sob o efeito da banalização do mal no exercício de atos civis comuns por parte dos que não são vítimas da exclusão (ou não o são ainda) e que contribuem para excluir parcelas cada vez maiores da população, agravando-lhes a adversidade.

Em outras palavras, a adesão à causa economicista, que separa a adversidade da injustiça, não resultaria, como se costuma crer, da mera resignação ou da constatação de impotência diante de um processo que nos transcende, mas funcionaria também como uma defesa contra a consciência dolorosa da própria cumplicidade, da própria colaboração e da própria responsabilidade no agravamento da adversidade social (Dejours, 1999, p. 21, último grifo nosso).

Assim, torna-se fundamental pontuar, ao se analisar a relação subjetividade-trabalho nas sociedades contemporâneas, que a inserção do trabalhador nesta nova organização produtiva não pode ser discutida fora da conjuntura maior da qual ela faz parte e onde a escassez e a precariedade dos postos de trabalho são uma realidade iniludível, com efeitos decisivos sobre o cotidiano dos sujeitos tanto dentro quanto fora do trabalho.

Em uma outra análise, ao comentar a passagem do 'Estado do bem-estar social' para o 'Estado neoliberal', Gorz (2003b) afirma:

El mensaje ideológico cambió: de 'qué importa el trabajo, siempre que el pago llegue a fin de mes', pasó a ser: 'qué importa el monto pago, siempre que se tenga empleo'. Dicho de otra manera: 'estén dispuestos a todas las concesiones, humillacionaes, sumisiones, competencias, traiciones para obtener o conservar un empleo; pues quien pierde el empleo, pierde todo'. Tal es, si no el sentimiento general, por lo menos el mensaje del discurso social dominante (Gorz, 2003b, p. 66).

Neste sentido, ainda que sem as condições ideais, o modelo produtivo do sistema de acumulação flexível, acoplado ao movimento de desterritorialização contínua que se produz no conjunto da sociedade, se oferece como possibilidade de construção de sentido, produzindo efeitos paradoxais sofrimento e bem-estar, alienação e emancipação - que precisam ser mais cuidadosamente examinados. 
Seguindo as observações críticas de Lourau (1990) sobre o desvio utilitarista do uso do conceito de implicação, localizamos algumas pistas para a continuação de nossa discussão. Conceito proposto pela análise institucional, a análise da implicação refere-se à análise dos vínculos afetivos, profissionais e políticos dos analistas-interventores-técnicos com as instituições em análise em determinado trabalho ou intervenção. 13 Entretanto, como observa argutamente esse autor, há alguns anos, a noção de implicação vem compartilhando uma 'nebulosa ideológica' com palavras como compromisso, participação, investimento afetivo, motivação, que muito tem a ver com nossas discussões anteriores.

'Eu me implico', 'ele não se implica o suficiente' são fórmulas que equivalem a versões novas de outras, velhas: 'eu me comprometo'; 'ele não se compromete realmente'. Tais fórmulas constituem juízos de valor sobre nós mesmos e sobre os demais, e destinam-se a traduzir o nosso grau de ativismo, de identificação com uma tarefa ou instituição, mensurando a quantidade de tempo/dinheiro que a essas dedicamos (estarmos ali presentes) como equivalente à carga afetiva que investimos na cooperação. É uma espécie de virtude teologal: a presença no mundo (Lourau, 1990, p. 1).

Assim, continuando suas considerações, Lourau nos mostra como uma 'síndrome da implicação' ou um 'implicacionismo' toma conta dos discursos das ciências sociais ao lado de uma burocratização de suas investigações onde pouco se fala ou se faz efetivamente a 'análise das implicações', fundamental em qualquer trabalho de cunho político e crítico. Neste sentido, o autor afirma: “(...) se o sistema fala de implicações é para impedir que sejam desveladas" (Lourau, 1990, p. 1) (como se vê também nas discussões de Sennett), abrindo aí o espaço para o que chamará de sobreimplicação.

De fato, a forma pronominal reflexiva do verbo implicar indica não somente aquela virtude teologal a que antes nos referimos, mas sobretudo o sobretrabalho exigido pela produção da mais-valia, da rentabilidade suplementar. Por sobretrabalho compreendemos algo diverso daquilo que seria simplesmente o dever do cidadão perante o Estado, o qual consiste, para os cristãos, no exercício correto de um ofício a fim de provar que não estão fora deste mundo. Reportamo-nos, então, ao que Jules Celma (1974) chama de 'exploração da subjetividade', que sucede à exploração da objetividade do homem no trabalho alienado - forma de sobre-exploração e sobre-repressão, no sentido marcusiano -, e nos autorizamos a propor o termo sobreimplicação para designar certa deriva do conceito de implicação relacionada à subjetividade-mercadoria.

A implicação é um nó de relações; não é boa (uso voluntarista), nem má (uso 
jurídico-policialesco). A sobreimplicação, por sua vez, é a ideologia normativa do sobretrabalho, gestora da necessidade do implicar-se (Lourau, 1990, p. 3-4).

E é esta necessidade - favorecida, como vimos, pela estrutura social contemporânea - que se faz presente o tempo todo na nova organização do trabalho; que torna, de alguma maneira, as 24 horas do dia em horário de trabalho, ainda que temporal e espacialmente fora dele. Trabalho, subjetividade e sobre-exploração ficam, neste espaço, portanto, intimamente ligados.

Vale ressaltar, ainda, que embora o sentimento de prazer não fique fora de toda esta engrenagem, ele vem acompanhado de ansiedade, agonia, culpa, solidão... que brotam da corrida contínua atrás das expectativas que o processo produtivo gera no seu cotidiano e do afastamento da vida familiar, comunitária e dos grupos de trabalho que se produz nesta corrida.

\section{Notas}

1 Professora-pesquisadora da Escola Politécnica de Saúde Joaquim Venâncio, da Fundação Oswaldo Cruz (EPSJV/Fiocruz), Rio de Janeiro, Brasil. Doutora em Psicologia Social pela Universidade do Estado do Rio de Janeiro (Uerj). <mlopes@fiocruz.br> Correspondência: Fundação Oswaldo Cruz, Escola Politécnica de Saúde Joaquim Venâncio, Avenida Brasil, 4.365, Manguinhos, Rio de Janeiro, Brasil, CEP 21040-900.

2 Ver, sobre o tema, Antunes (2005).

3 Ver, sobre o tema, Foucault (1989b).

4 Este texto e sua datação referem-se, basicamente, ao processo de reestruturação produtiva europeu que só foi implementado, mais agressivamente, no Brasil, a partir dos anos 90.

5 Como sujeito trabalhador nos referimos a um determinado padrão produzido que não se remete unicamente ao sujeito que está trabalhando, empregado. Pois este padrão afeta não somente os inseridos no mercado de trabalho, mas também aqueles que dele não participam e desejam participar. Aqui, a noção de empregabilidade - e a busca constante dos sujeitos por ela - aparece como fundamental.

6 Estamos chamando estruturas sociossubjetivas a um conjunto de estruturas históricas e culturais que produzem os contornos dos processos sociais e subjetivos.

7 Define-se evento como algo não previsto, que perturba o desenvolvimento 'normal' do sistema de produção e que ultrapassa a capacidade automatizada de assegurar sua autorregulação.

$8 \mathrm{O}$ primeiro ingrediente refere-se à capacidade humana de criar conceitos, de repetir determinadas operações visando ao controle da variabilidade do meio; o segundo refere-se 
à dimensão de experiência, significa estar apto a lidar com os imprevistos e a singularidade das diferentes situações de trabalho; o terceiro diz respeito à possibilidade de instaurar uma dialética entre os dois primeiros ingredientes; o quarto refere-se à relação entre a atividade, o estabelecimento da dialética própria do ingrediente três e os valores que se desenvolvem no meio de trabalho, incluindo aí definitivamente a política de gestão como condição para o desenvolvimento da competência; o quinto aponta para a relação deste quarto ingrediente com os dois primeiros; o ingrediente seis refere-se à 'qualidade sinergética', à possibilidade de construção de equilíbrios, sempre provisórios, que transformam os desempenhos e competências individuais, envolvendo aí, definitivamente, a política global de gerência do ambiente de trabalho no desenvolvimento das competências.

9 Mesmo na organização de trabalho fordista mais rígida, é possível assinalar esta dramática.

10 Define-se figura de autoridade, aqui, como "alguém que assume a responsabilidade pelo poder que usa" (Sennett, 1999, p. 136). Assim, "a ausência de verdadeiros seres humanos dizendo 'Eu lhe digo o que fazer' ou, no caso extremo, 'Vou fazer você pagar por isso', é mais que um ato defensivo dentro da empresa; essa ausência de autoridade deixa livres os que estão no controle para mudar, adaptar, reorganizar, sem ter de justificar-se ou a seus atos. Em outras palavras, permite a liberdade do momento, um foco apenas no presente. A mudança é o agente responsável; e não é uma pessoa. Além disso, poder sem autoridade permite aos líderes de uma equipe dominar os empregados negando legitimidade às suas necessidades e desejos" (Sennett, 1999, p. 136).

11 Como vimos anteriormente, a organização do trabalho fordista deixa espaços muito pequenos para a iniciativa e a criatividade dos trabalhadores.

12 Vale observar, aqui, que Gorz utiliza como base o trabalho industrial, o que, entretanto, não invalida suas observações.

13 Ver, sobre o tema, entre outros, Rodrigues (1987).

\section{Referências}

ANTUNES, Ricardo. Adeus ao trabalho?: Ensaio sobre as metamorfoses e a centralidade do mundo do trabalho. São Paulo: Cortez, 1997.

O caracol e sua concha. São Paulo:

Boitempo, 2005.

ARAÚJO, Anísio et al. (Orgs.). Cenários do trabalho. Rio de Janeiro: DP\&A, 2004.
BORGES, Luiz H. F. et al. (Orgs.). Organização do trabalho e saúde: múltiplas relações. Vitória: Edufes, 2001

BRITO, Jussara. Saúde do trabalhador: reflexões a partir da abordagem ergológica. In: FIGUEIREDO, Marcelo et al. (Orgs.). Labirintos do trabalho. Rio de Janeiro: DP\&A, 2004. p. 91-114. 
CANGUILHEM, Georges. O normal e o patológico. 3. ed. Rio de Janeiro: Forense Universitária, 1990.

CELMA, Jules. Journal d'un éducastreur. Paris: Anthropos, 1974 apud LOURAU, René. Implication et sobreimplication. Mauss (Mouvement Anti-utilitariste dans les Sciences Sociales), v. 10, n. 4, 1990.

COLBARI, Antonia. Resistência e adesão no universo das relações de trabalho. In: BORGES, Luiz H. et al. (Orgs.) Organização do trabalho e saúde: múltiplas relações. Vitória: Edufes, 2001, p. 113-131.

DEJOURS, Christophe. A loucura do trabalho. 5. ed. ampliada. São Paulo: Cortez, 1992.

A banalização da injustiça social. Rio de Janeiro: Ed. FGV, 1999.

DEJOURS, Christophe; ABDOUCHELI, Elisabeth; JAYET, Christian. Psicodinâmica do trabalho: contribuições da Escola Dejouriana à análise da relação prazer, sofrimento e trabalho. São Paulo: Atlas, 1994.

DUARTE, Luiz. F. Da vida nervosa nas classes trabalhadoras urbanas. Rio de Janeiro: Zahar, 1986.

FIGUEIREDO, Marcelo et al. (Orgs.) Labirintos do trabalho. Rio de Janeiro: DP\&A, 2004.

FONSECA, Taniat M. G. Modos de trabalhar, modos de subjetivar em tempos de reestruturação produtiva. In: Modos de trabalhar, modos de subjetivar. Porto Alegre: Ed. UFRGS, 2002, p. 13-27.

FOUCAULT, Michel. Microfísica do poder. 8. ed. Rio de Janeiro: Graal, 1989a.

Vigiar e punir: história da violência nas prisões. 7. ed. Petrópolis: Vozes, 1989b.

GORZ, Andre. Miserias del presente, riqueza de lo possible. 2. ed. Buenos Aires: Paidós, 2003a.
- Metamorfoses do trabalho: crítica

da razão econômica. São Paulo: Anna Blume, 2003b.

HARVEY, David. Condição pós-moderna. 10. ed. São Paulo: Edições Loyola, 2001.

LOURAU, René. La clé des champs. 1995. Mimeografado.

Implicação e sobreimplicação. 1990.

Mimeografado.

MENDES, Ana M. et al. (Orgs.). Trabalho em transição, saúde em risco. Brasília: Ed. UnB, 2002.

NEVES, Mary. Y.; SELIGMANN-SILVA, Edith.; ATHAYDE, Milton (Orgs.) Saúde mental e trabalho: um campo de estudo em construção. In: ARAÚJO, Anísio et al. Cenários do trabalho. Rio de Janeiro: DP\&A, 2004.

RAGO, Margareth. Do cabaré ao lar. 3 ed. Rio de Janeiro: Paz e Terra, 1997.

RAMOS, Marise. A pedagogia das competências. São Paulo: Cortez, 2001.

É possível uma pedagogia das competências contra-hegemônica? Trabalho, Educação e Saúde. Rio de Janeiro, v. 1, n. 1, p. 93-114, mar. 2003.

O projeto unitário de ensino médio sob os princípios do trabalho, da ciência e da cultura. In: FRIGOTTO, Gaudêncio; CIAVATTA, Maria. Ensino médio: ciência, cultura e trabalho. Brasília: MEC, 2004.

ROSA, Maria. I. Do governo dos homens: 'novas responsabilidades' do trabalhador e acesso aos conhecimentos. Educação e Sociedade. Campinas, n. 64, especial, p. 130147, set. 1998.

SCHWARTZ, Yves. Os ingredientes da competência: Um exercício necessário para uma questão insolúvel. Educação $e$ Sociedade. Campinas, v. 19, n. 65, p. 101140, dez. 1998. 
. Trabalho e gestão: níveis, critérios, instâncias. In: FIGUEIREDO, Marcelo et al. (Orgs.) Labirintos do trabalho. Rio de Janeiro: DP\&A, 2004, p.23-36.

SENNETT, Richard. A corrosão do caráter. Rio de Janeiro: Record, 1999.

VERNANT, Jean Pierre. Trabalho e natureza na Grécia Antiga. In: VERNANT, Jean
Pierre; NAQUET, Pierre. Trabalho e escravidão na Grécia Antiga. Campinas: Papirus, 1989 , p. 9-33.

ZARIFIAN, Philippe. Objetivo competência: por uma nova lógica. São Paulo: Atlas, 2001.

Recebido em 08/10/2007

Aprovado em 13/07/2008 